\title{
Microstructure evolution of fibre laser welded TRIP and HSLA steel sheets with different thicknesses
}

\author{
P. Švec ${ }^{1 *}$, A. Schrek ${ }^{1}$, M. Dománková ${ }^{2}$ \\ ${ }^{1}$ Institute of Technologies and Materials, Faculty of Mechanical Engineering, \\ Slovak University of Technology in Bratislava, Pionierska 15, 83102 Bratislava, Slovak Republic \\ ${ }^{2}$ Institute of Materials Science, Faculty of Materials Science and Technology in Trnava, \\ Slovak University of Technology in Bratislava, Bottova 25, 91724 Trnava, Slovak Republic
}

Received 5 March 2019, received in revised form 16 April 2019, accepted 2 May 2019

\begin{abstract}
The microstructure of fibre laser welded joint of TRIP 690T and HSLA LAD340 steel sheets with different thicknesses was evaluated. The microstructure in the fusion zone was built of martensite, lower bainite and a small portion of upper bainite. Martensite and lower bainite created in both the coarse-grained and fine-grained heat affected zones (HAZs) near $690 \mathrm{~T}$ steel, but some portion of ferrite was also identified in the fine-grained HAZ near 690T steel. Acicular ferrite, upper bainite, and equiaxed ferrite were observed in both the coarsegrained and fine-grained HAZs near LAD340 steel, but lower bainite was occasionally found in the coarse-grained HAZ near LAD340 steel. Creation of hard microconstituents caused an increase in microhardness values in the fusion zone and both HAZs compared to the base metals. The highest microhardness of $457 \mathrm{HV}_{0.1}$ was measured in the coarse-grained HAZ near $690 \mathrm{~T}$ steel with martensitic and lower bainitic microstructure.
\end{abstract}

K e y w or d s: TRIP steel, HSLA steel, fibre laser welding, microstructure

\section{Introduction}

In recent years, advanced high strength steels (AHSSs) steels have received significant research interest because of their excellent combination of strength and ductility with low price. AHSSs are mainly used in the automotive industry for the components responsible for car body strength and energy absorption [1-4]. Due to their increased use, vehicle weight can be reduced without compromising both passenger safety and environmental requirements. Their application in the automotive industry is rapidly increasing mainly in the tailor welded blanks (TWBs) [5-7]. Two dissimilar steel sheets with different thicknesses can be integrated into TWBs to fit application before the blank goes through the forming process. Using TWBs enables an adaptation to locally different loading conditions or other requirements in the parts and leads to lighter, less expensive parts that are functionally superior $[7,8]$. Frames, various beams, and safety elements are often made of TWBs consisting of AHSS steels. A body-in-white manufactured using TWBs and AHSSs can achieve a significant (above $25 \%$ ) weight reduction. Joining transformation induced plasticity (TRIP) steels with high strength low alloyed (HSLA) steels in TWBs enables to utilise their advantageous properties in the design of several energy absorbing parts such as front and rear rails of a car. In these parts, thicker sheets of TRIP steel with thinner sheets of AHSS steel can meet the required properties $[7,9,10]$.

Transformation induced plasticity (TRIP) steels are a unique group of AHSSs exhibiting the TRIP effect. As a result of the thermomechanical treatment during the manufacturing of metal sheet, TRIP steel has a rather complex microstructure. It is composed of a ferrite matrix (about 50\%) with some portion of bainite along with dispersed islands of martensite and a fraction of retained austenite (from 10 to $15 \%$ ) $[10,11]$. TRIP steels have an excellent combination of strength and ductility, due to a high work hardening rate caused by the transformation of retained

*Corresponding author: tel.: +421 905326211; e-mail address: pavol.svec@stuba.sk 
Ta ble 1. Maximal concentration of alloying elements in wt.\% for $690 \mathrm{~T}$ and LAD340 steel

\begin{tabular}{lcccccccccccc}
\hline Steel & $\mathrm{C}$ & $\mathrm{Mn}$ & $\mathrm{Si}$ & $\mathrm{Al}$ & $\mathrm{P}$ & $\mathrm{S}$ & $\mathrm{V}$ & $\mathrm{B}$ & $\mathrm{Nb}$ & $\mathrm{Ti}$ & $\mathrm{Cr}+\mathrm{Mo}$ & $\mathrm{Nb}+\mathrm{Ti}$ \\
\hline 690T & 0.32 & 2.5 & 2.2 & 2.0 & 0.12 & 0.015 & 0.2 & 0.005 & - & - & 0.60 & 0.20 \\
LAD340 & 0.11 & 1.0 & 0.5 & 0.015 & 0.03 & 0.025 & - & - & 0.09 & 0.15 & - & - \\
\hline
\end{tabular}

Ta b le 2. Mechanical properties of 690T and LAD340 steel

\begin{tabular}{lccc}
\hline Steel & Tensile strength $(\mathrm{MPa})$ & Proof strength $(\mathrm{MPa})$ & Elongation $(\%)$ \\
\hline $690 \mathrm{~T}$ & $980-1130$ & $660-780$ & $\min .10$ \\
LAD340 & $410-510$ & $340-420$ & min. 21 \\
\hline
\end{tabular}

austenite to martensite during plastic deformation. The martensite transformation of the retained austenite avoids localised deformation, leading to the comparatively large homogeneous elongation obtained in these steels [12, 13]. The martensite transformation takes place during sheet metal forming and can be exploited when making sections of highly complicated shapes enabling the safety improvement by increasing the amount of absorbed collision energy. TRIP steels can reach maximum tensile stress above 1200 MPa with a uniform elongation up to $14 \%$ [14]. Such an exceptional structure property connection is taken into consideration for body-in-white designs where significant stretch forming is required. TRIP steels are applied in automotive structural components such as B-pillar, engine cradle, front and rear rails $[15,16]$.

High strength low alloyed (HSLA) steels are the fine-grained materials with good strength-to-weight ratio at low concentration of carbon and alloying elements. Due to their chemical composition and special thermomechanical treatment, HSLA steels have mainly ferritic matrix with a fine dispersion of alloy carbides. This microstructure is the consequence of lower strength, but better formability and weldability compared to TRIP steels. Their yield strengths can be up to $590 \mathrm{MPa}$. Although they are predominately used in structural applications such as cranes, bridges, roller coasters, their application in the auto industry is rapidly increasing mainly in TWBs [16-19].

In the automotive industry, AHSS are mainly joined by laser beam welding mostly used in the production of TWBs. Among various types of lasers, the fibre lasers have found many applications in car body manufacturing because of their excellent beam quality and high brightness. Fibre laser welding offers the benefits of low heat input per unit volume, small fusion zone (FZ), small heat affected zone (HAZ), low thermal distortion of the workpiece, fewer welding defects, high welding speed, and deep and narrow weld profiles. Also, it allows for easy automation while welding complex joint configurations and dissimilar materials $[2,20-22]$. However, laser welding has some dis- advantages that include the need for almost press fitting of parts due to its small, focused spot size, high equipment, and operating costs. Low heat input is a very important characteristic of laser welding, and it is the consequence of small FZ and HAZ with the finegrained microstructures that provide the strength and toughness of the joint [21-24].

During the welding process, the sophisticated designed microstructures of both TRIP and HSLA steels are destroyed, and beneficial transformation of retained austenite to martensite in TRIP steel cannot be utilised in the weld region $[11,15]$. Microstructure changes accompanying the fibre laser welding generally increase the strength and worsen the formability in the weld region of these steels. However, softening at the sub-critical HAZ of TRIP steels is possible at some welding parameters. The microstructure is created in thermal cycles with different maximal temperatures and with heating and cooling in significantly short times. The microstructure is affected mainly by the chemical composition of base materials, sheets thicknesses and welding parameters such as power input, welding speed, and others [25-28]. The microstructure of laser welded TRIP steels was studied in several works, but there is less information about welding of TRIP with HSLA steels. Moreover, the information about the microstructure of these welds is different $[5,10-13,15,16]$. Therefore, it is useful to study the evolution of microstructure of TRIP with HSLA steel joints.

\section{Experiment}

The TRIP 690T steel sheet with a thickness of $1.5 \mathrm{~mm}$ and HSLA LAD340 steel sheet with a thickness of $1.2 \mathrm{~mm}$ were used for fibre laser welding. The experimental sheets had the same zinc coating of $100 \mathrm{~g} \mathrm{~m}^{-2}$. The maximal concentrations of alloying elements in both sheets of steel are given in Table 1 and their mechanical properties are compared in Table 2. The TRIP 690T steel has higher strength, but the 


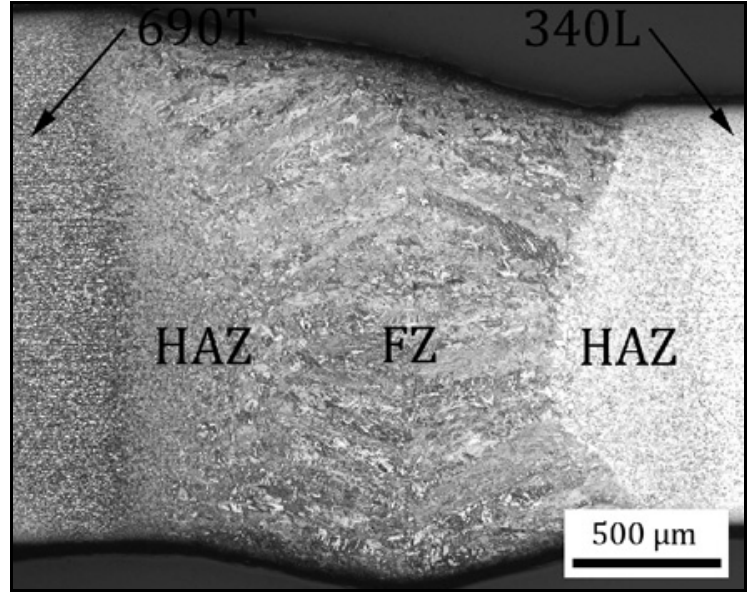

Fig. 1. The macrostructure of fibre laser welded joint of $690 \mathrm{~T}$ and LAD340 steel sheets, LM (FZ - fusion zone, HAZ - heat affected zone).

LAD340 steel has higher ductility which goes along with different chemical compositions of these steels.

The experimental steel sheets were butt welded using the solid-state fibre laser YLS 5000 S-1 from IPG Photonics company with a maximum output of $5000 \mathrm{~W}$, the wavelength of $1060 \mathrm{~nm}$ and fibre diameter of $100 \mu \mathrm{m}$. The device is equipped with the welding head Precitec YW52. The welding head was positioned at a distance of $250 \mathrm{~mm}$ from the welded sheets with a length of $200 \mathrm{~mm}$ and a width of $100 \mathrm{~mm}$. Welding experiments were conducted along the longitudinal edges of sheets and undersides of sheets were fixed in the same plane at the root of the joints. The butt joints were prepared at different beam power and welding speed, and without welding gap, filler metal and shielding atmosphere. However, the joint of $690 \mathrm{~T}$ and LAD340 steel prepared at the beam power of $3600 \mathrm{~W}$ and welding speed of $70 \mathrm{~mm} \mathrm{~s}^{-1}$ was chosen for detailed microstructure observation, because these parameters enabled to prepare proper macrostructure of the weld at the highest welding speed.

The fibre laser weld surfaces were observed using the stereomicroscope Zeiss Technival 2. The macrostructures and microstructures of welds were studied on transverse cross-sections. These were cut off the fibre laser welded joints and prepared using standard metallographic techniques. Light microscopy (LM) with Axiovert 40MAT light microscope and scanning electron microscopy (SEM) with JEOL JSM-IT300 scanning electron microscope with an accelerating voltage of $15 \mathrm{kV}$ were used for microstructural characterisation of samples. Energy-dispersive spectroscopy (EDS) with an accelerating voltage of $15 \mathrm{kV}$ was employed for chemical analysis of created phases. The grain size was measured by image analysis using Multiphase module of AxioVision software. Both carbon replica samples and thin film samples were prepared for transmission electron microscopy (TEM) analysis. TEM samples were observed using two transmission electron microscopes JEOL 200 CX with an accelerating voltage of $200 \mathrm{kV}$ and Philips CM 300 with an accelerating voltage of $300 \mathrm{kV}$. Selected area electron diffraction (SAED) was used for qualitative phase analysis of weld sub-zones when studying thin film samples. Microhardness surveys were performed on transverse cross-sections of welds parallel to the surfaces of sheets using Vickers indenter with a load of $100 \mathrm{~g}$. Flat tensile test specimens with a gage length of $60 \mathrm{~mm}$ and width of $15 \mathrm{~mm}$ with $\mathrm{FZ}$ in the centre of samples were prepared from welded joints and tests were carried out using testing machine Instron 195 at a crosshead speed of $10 \mathrm{~mm} \mathrm{~min}^{-1}$ according to the EN ISO 6892-1 standard.

\section{Results}

\subsection{Macrostructure of fibre laser welded joint}

Figure 1 depicts the transverse cross-section of fibre laser welded joint prepared at the beam power of $3600 \mathrm{~W}$ and the welding speed of $70 \mathrm{~m} \mathrm{~s}^{-1}$. A fully penetrated weld with its typical sub-zones can be seen in Fig. 1. The FZ of joint is characterised by $\mathrm{X}$ shape and the formation of columnar grains. The 690T steel BM has a thickness of $1.5 \mathrm{~mm}$, and the LAD340 steel BM has a thickness of $1.2 \mathrm{~mm}$ with undersides of sheets placed in the same plane. Both HAZs are bounded by quite narrow interfaces with BMs. The macrostructure of weld zones revealed the absence of macro defects, such as pores and cracks, but the joint is characterised with the slight undercut at the face on the side of LAD340 steel and root sagging. The grain size within both HAZs varies accordingly different peak temperatures reached during the thermal welding cycle which are the most important factors in determining the microstructural evolution. The grain size in both HAZs decreases with the distance from the weld boundaries. The coarse-grained regions can be seen in the vicinity of the FZ with the highest peak temperatures in the super-critical HAZs above $A_{\mathrm{c} 3}$ critical temperature. The fine-grained regions are located further towards the BMs in the inter-critical temperature interval from $A_{\mathrm{c} 1}$ to $A_{\mathrm{c} 3}$.

\subsection{Microstructures of base metals}

The SEM micrograph revealing the microstructure of TRIP 690T steel is documented in Fig. 2. The 690T BM has a typical TRIP-type microstructure consisting of ferrite, lower bainite and retained austenite. The equiaxed ferritic grains are characterised by slight crystallographic texture and grain size from 1 to $8 \mu \mathrm{m}$. Martensite and retained austenite microconstituents 


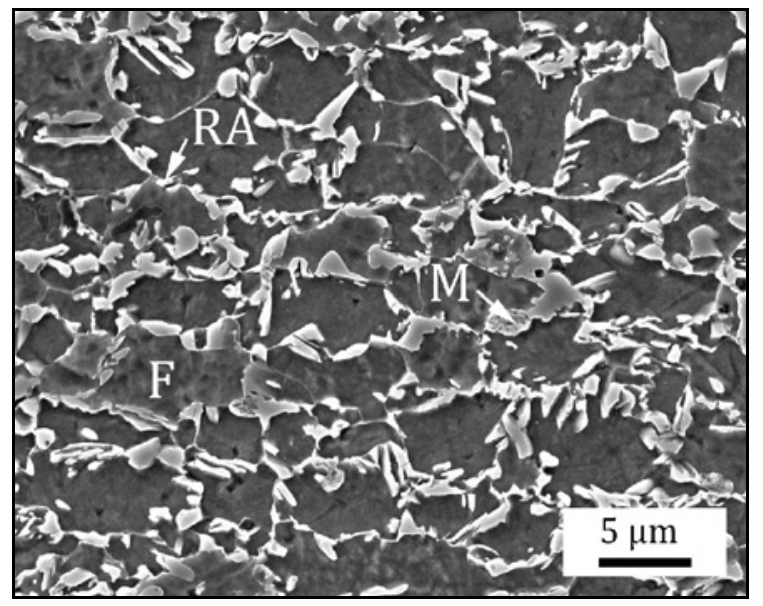

Fig. 2. The microstructure of the 690T TRIP steel, SEM ( $\mathrm{F}$ - ferrite, $\mathrm{M}$ - martensite, $\mathrm{RA}$ - retained austenite).

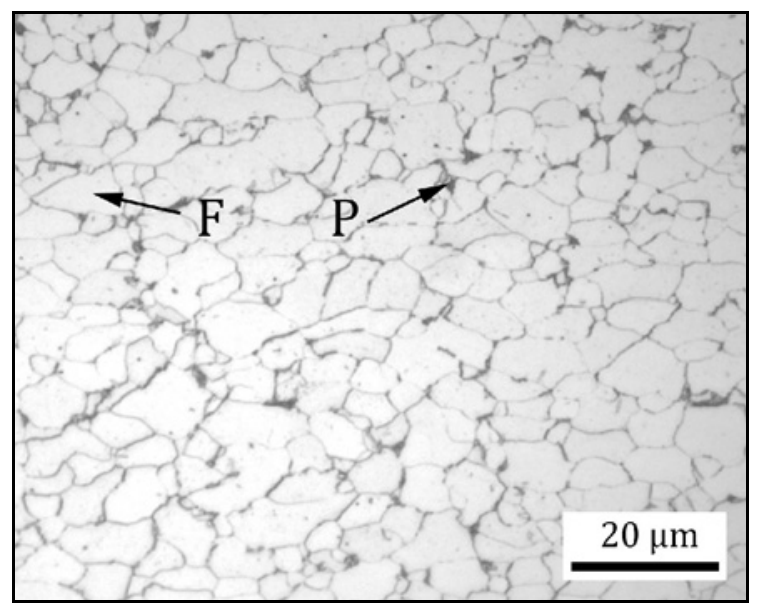

Fig. 3. The microstructure of LAD340 HSLA steel, LM ( $\mathrm{F}$ - ferrite, $\mathrm{P}$ - pearlite).

are placed in rows. Occasionally precipitated $\mathrm{M}_{3} \mathrm{C}$ carbides were identified by EDS analysis inside the grains.

The microstructure of HSLA LAD340 steel in Fig. 3 has mainly equiaxed morphology. The matrix of LAD340 BM is built by equiaxed ferrite with slight heterogeneity in the grain size in the interval from 2 to $15 \mu \mathrm{m}$. Small islands of pearlite, tertiary cementite and carbides were observed and identified using EDS analysis at the ferritic grain boundaries.

\subsection{The microstructure of the fusion zone}

When studying the microstructure evolution in the sub-zones of joint, the observation was firstly concerned on the microstructure of the FZ which is depicted in detail from Fig. 4 to 8. The microstructures in both HAZs were observed in the coarse-grained and

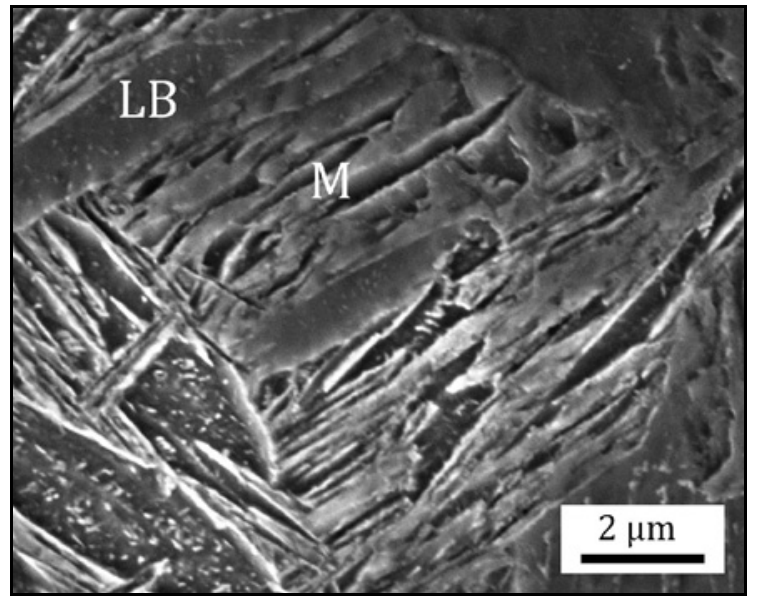

Fig. 4. The microstructure in $\mathrm{FZ}$ of fibre laser welded joint, SEM (LB - lower bainite, M - martensite).
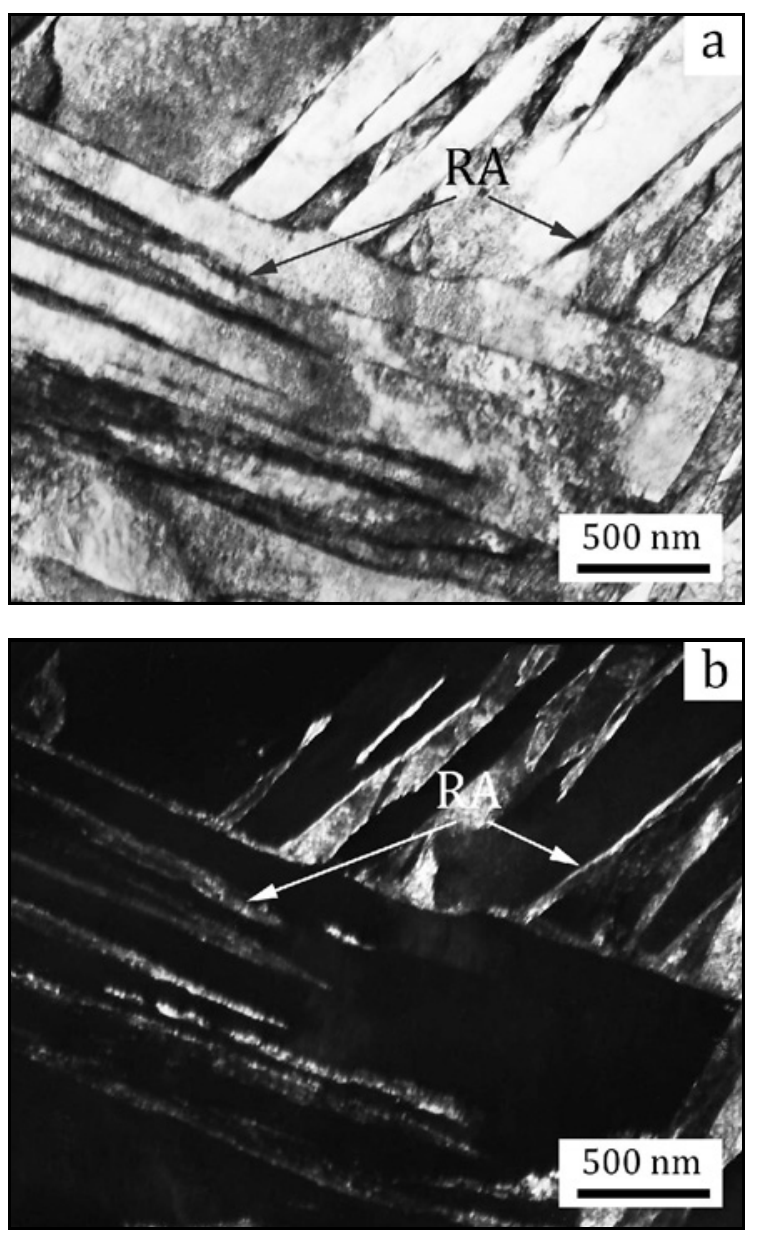

Fig. 5. Martensite laths with retained austenite (RA) in FZ of the weld (a) bright field TEM image and (b) dark field TEM image with reflections of retained austenite.

fine-grained HAZs. Micrographs from these zones are presented in Figs. 9-16. 

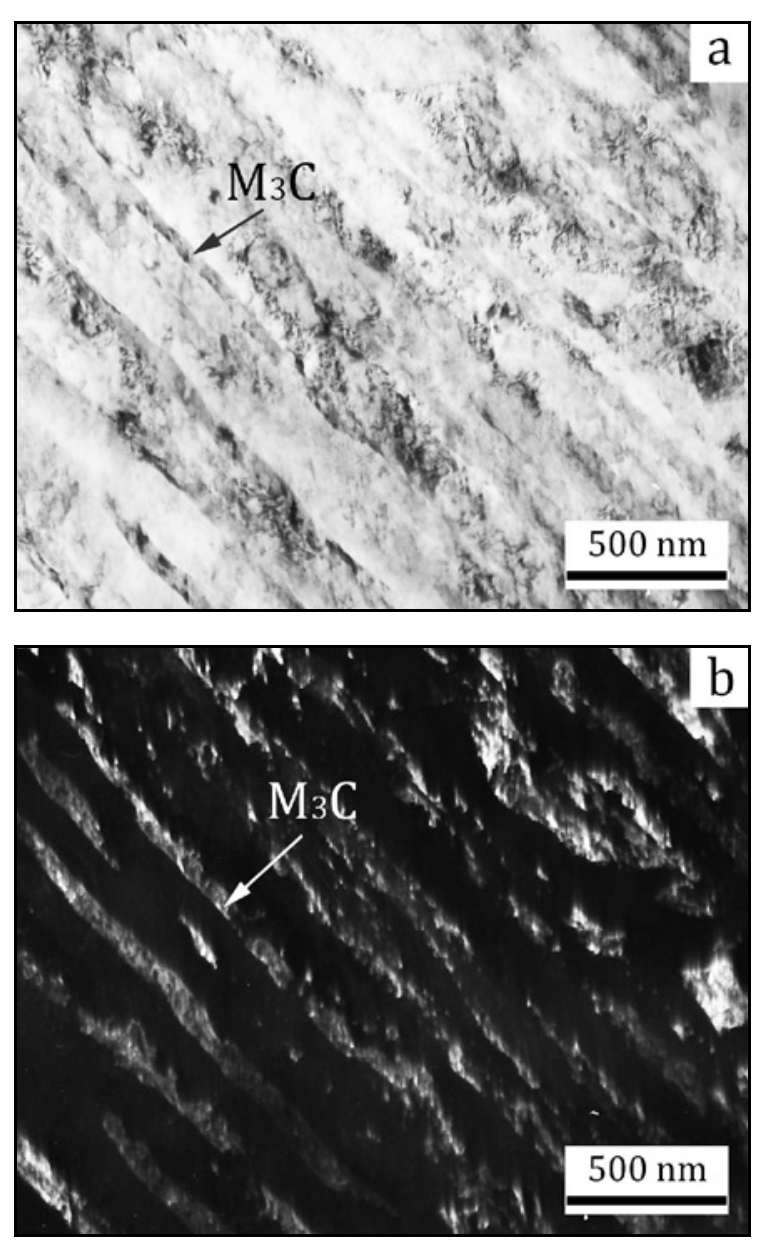

Fig. 6. Lower bainite in FZ of the weld (a) bright field TEM image and (b) dark field TEM image with reflections of $\mathrm{M}_{3} \mathrm{C}$ carbide precipitates.

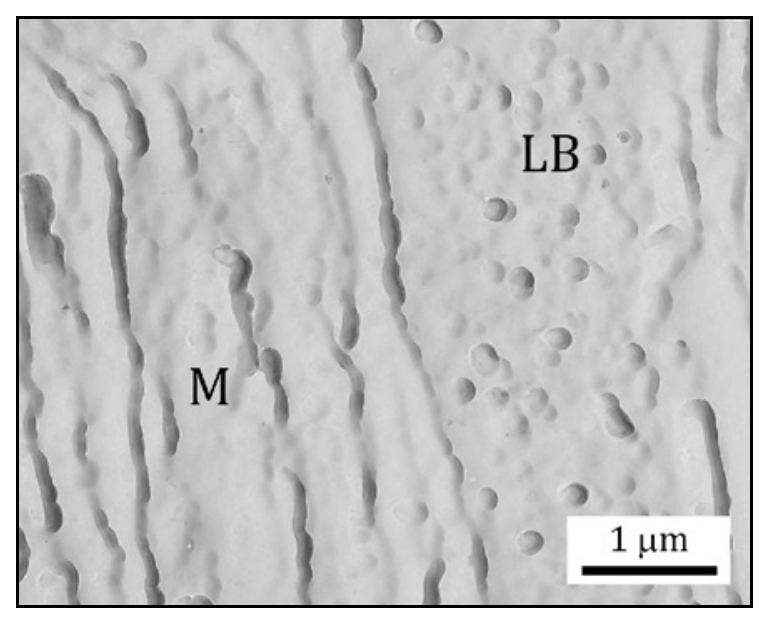

Fig. 7. Martensite (M) and lower bainite (LB) in FZ of fibre laser welded joint, TEM.

The SEM microstructure in FZ of fibre laser welded joint is depicted in Fig. 4. The chemical composition

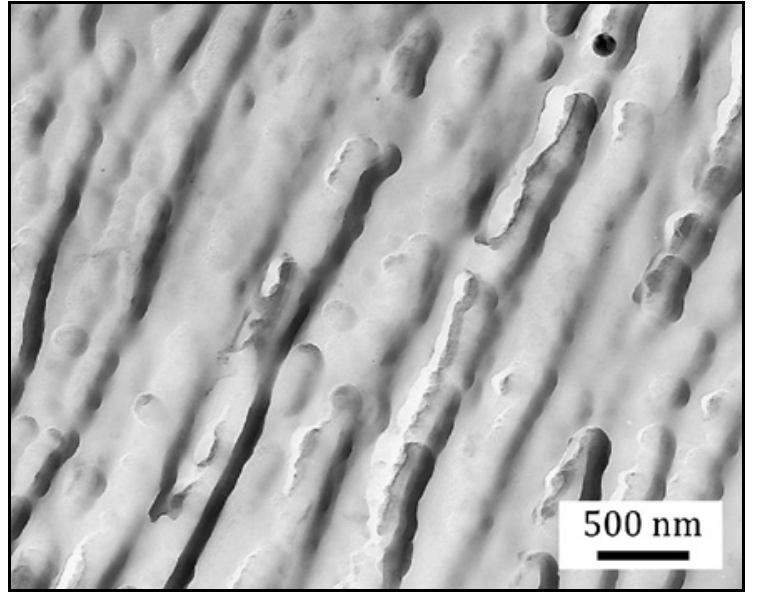

Fig. 8. Upper bainite (UB) in FZ of fibre laser welded joint, TEM.

of the fusion zone was not measured, but the concentrations of alloying elements should be in the interval bordered by their concentrations in the welded steel sheets (Table 1). The microstructure of FZ is predominantly built of lath microconstituents. It consists of martensitic microstructure with some portion of lower bainite and occasionally of upper bainite. Laths of these microconstituents are built in packets and blocks within a large columnar grain structure and were the consequence of rapid cooling. The identification of the microconstituents created in FZ was confirmed using TEM. Thin film samples are in details documented in Figs. 5 and 6 and carbon replicas are in Figs. 7 and 8 .

Typical characteristics of low carbon lath martensite with retained austenite between martensitic laths can be identified in Fig. 5. Two blocks with martensitic laths inside them at an angle of $60^{\circ}$ are documented in bright field image in Fig. 5a. The dark field image of the same microstructure with reflections of austenite in Fig. 5b confirms the identification of microstructure.

The bright field TEM image of lower bainite is depicted in Fig. 6a. Block of bainitic laths with the same orientation and $\mathrm{M}_{3} \mathrm{C}$ carbide precipitates inside the laths are visible in dark field image with reflections of $\mathrm{M}_{3} \mathrm{C}$ carbide precipitates in Fig. 6b.

Morphological characteristics of low carbon lath martensite and lower bainite with carbide precipitates inside the bainitic lath are documented in carbon replica in Fig. 7. Figure 8 shows occasionally observed upper bainite. Upper bainite is characterised by more straightened laths compared to martensite and with imprints of carbides which precipitated at the lath boundaries.

\subsection{The microstructure of $H A Z$ near TRIP 690T steel}

The microstructure within HAZ near TRIP 690T 


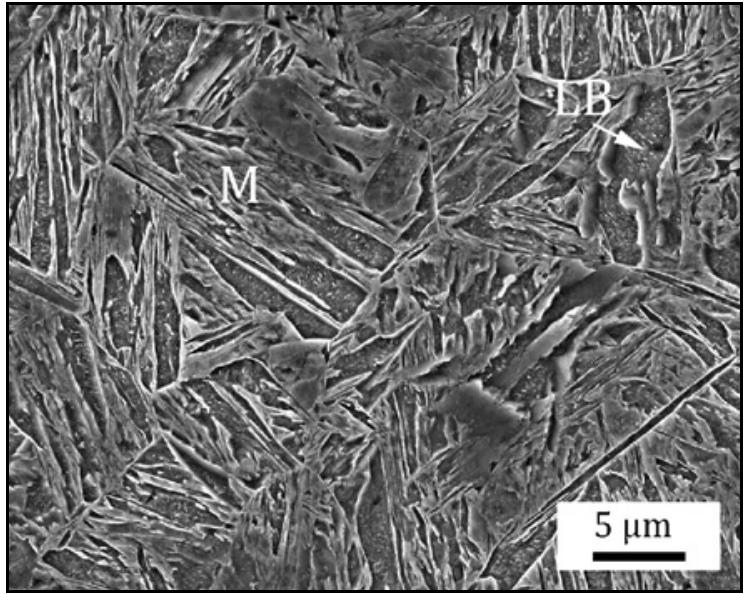

Fig. 9. The microstructure of the coarse-grained HAZ near 690T steel, SEM (M - martensite, LB - lower bainite).

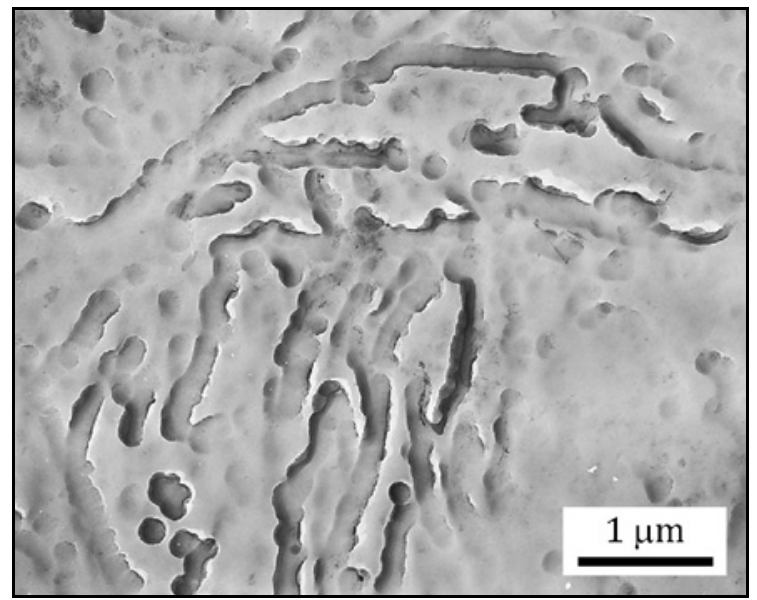

Fig. 10. Martensite in the coarse-grained HAZ near 690T steel, TEM.

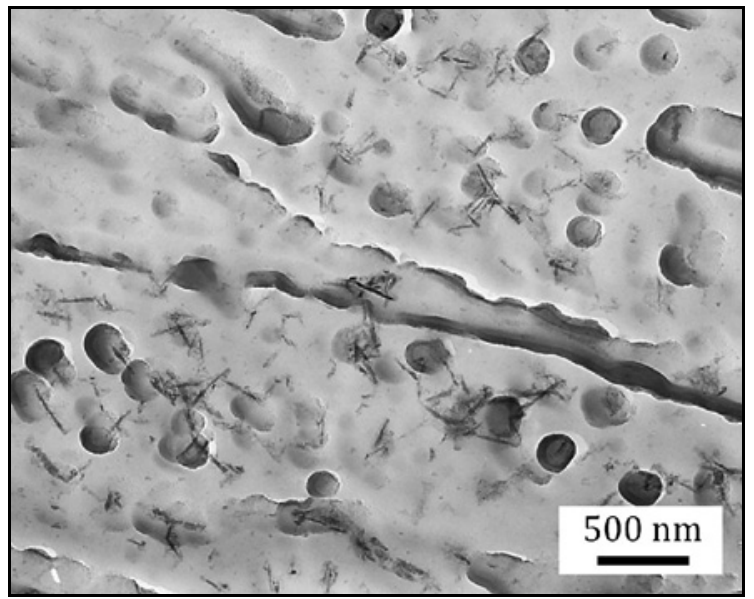

Fig. 11. Lower bainite in the coarse-grained HAZ near $690 \mathrm{~T}$ steel, TEM.

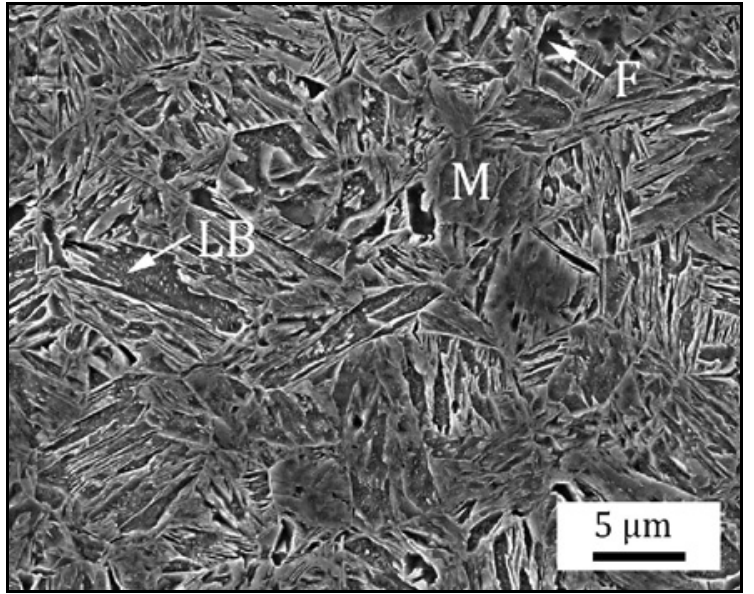

Fig. 12. Microstructures of the fine-grained HAZ near 690T steel, SEM (M - martensite, LB - lower bainite, $\mathrm{F}$ - ferrite).

steel is in general rather inhomogeneous reflecting the maximal temperatures achieved during the fibre laser welding. The microstructure varies at different locations further away from the FZ, and this variation is documented from Figs. 9 to 12 with a concentration on both the coarse-grained and fine-grained region of $\mathrm{HAZ}$. The coarse-grained $\mathrm{HAZ}$ is in the vicinity of $\mathrm{FZ}$ with the maximal temperatures reaching values above the upper transformation temperature $A_{\mathrm{c} 3}$. A complete austenitization followed by grain growth with grain size in the interval from 35 to $55 \mu \mathrm{m}$ can be observed in this region in Fig. 9. Upon cooling, the coarse-grained HAZ near 690T steel transforms austenite mainly to martensite and lower bainite. The mainly martensitic microstructure was observed at laser welding of TRIP steel in work [27].

Details of lath martensite and lower bainite with imprints of precipitates inside bainitic laths are depicted using TEM carbon replicas in Figs. 10 and 11. The morphologies of these microconstituents are the same as at the microstructures observed in FZ of the weld (see Fig. 7).

The fine-grained HAZ near 690T steel in Fig. 12 is located further away from the $\mathrm{FZ}$ and is characterised by temperatures within the inter-critical zone between the $A_{\mathrm{c} 3}$ and $A_{\mathrm{c} 1}$. This region is only partly austenitized during welding, and the microstructure consists of martensite, lower bainite, and a small portion of ferrite. The microconstituents in Fig. 12 are finer compared to the coarse-grained region in Fig. 9. At a further distance from the weld centre, increased portion of ferrite phase was observed because maximal temperature peak decreased during the welding process with the distance from the weld centre. 


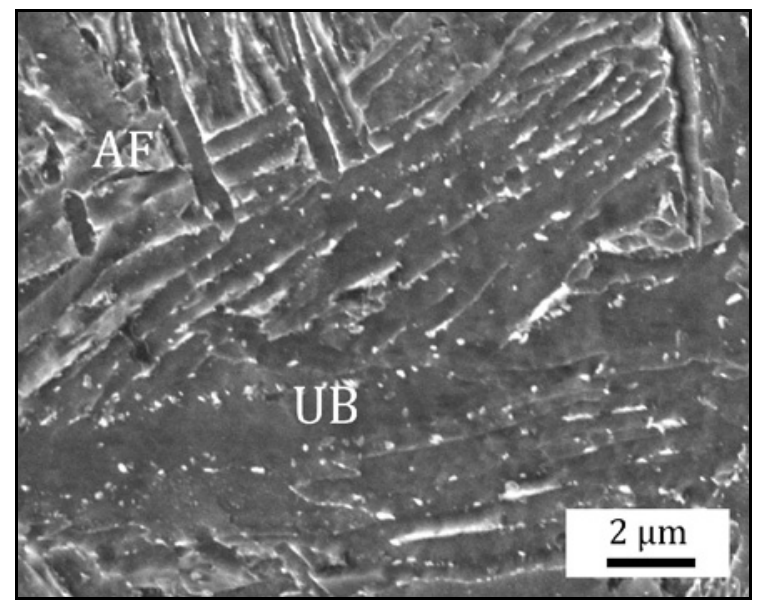

Fig. 13. The microstructure of the coarse-grained HAZ near LAD340 steel, SEM (UB - upper bainite, AF - acicular ferrite).

\subsection{The microstructure of $H A Z$ near $H S L A$ LAD340 steel}

The microstructure of HAZ near HSLA LAD340 steel can be seen from Fig. 13 to Fig. 16. A smaller portion of hard microstructures was created in this HAZ, because of smaller content of carbon and alloying elements in LAD340 steel compared to TRIP $690 \mathrm{~T}$ steel. In the coarse-grained HAZ near LAD340 steel, the coarsening of former austenitic grains was observed with the average grain size from 20 to $30 \mu \mathrm{m}$. The microstructure was built of acicular ferrite, upper bainite, lower bainite, and equiaxed ferrite which precipitated at former austenitic grain. The same microstructure consisting of acicular ferrite, upper bainite, and equiaxed ferrite was identified in the coarsegrained HAZ near HSLA LAD340 steel when fibre laser welding of dual-phase DP980 steel with HSLA LAD340 steel at similar welding parameters [29]. In work [27], the microstructure in super-critical HAZ of HSLA steel with $0.08 \mathrm{C}, 0.8 \mathrm{Mn}, 0.5 \mathrm{Si}$, and $0.05 \mathrm{Al}$ was built of martensite and bainite.

A TEM micrograph of upper bainite laths and acicular ferrite in the coarse-grained HAZ near LAD340 steel is presented in Fig. 14. TEM microstructure consisting of equiaxed ferrite with occasionally created lower bainite is depicted in Fig. 15. Martensite was not found in the HAZ near LAD340 steel.

In the inter-critical region of HAZ near HSLA steel LAD340 the fine-grained mainly equiaxed ferritic microstructure with average grain size from 2 to $5 \mu \mathrm{m}$ was observed and is documented in Fig. 16. Small areas of acicular ferrite and upper bainite were also identified in the fine-grained HAZ near LAD340 steel (see Fig. 16). Many precipitates probably carbides were observed inside the ferrite phase as can be seen in Fig. 16. At fibre laser welding of dual-phase DP980

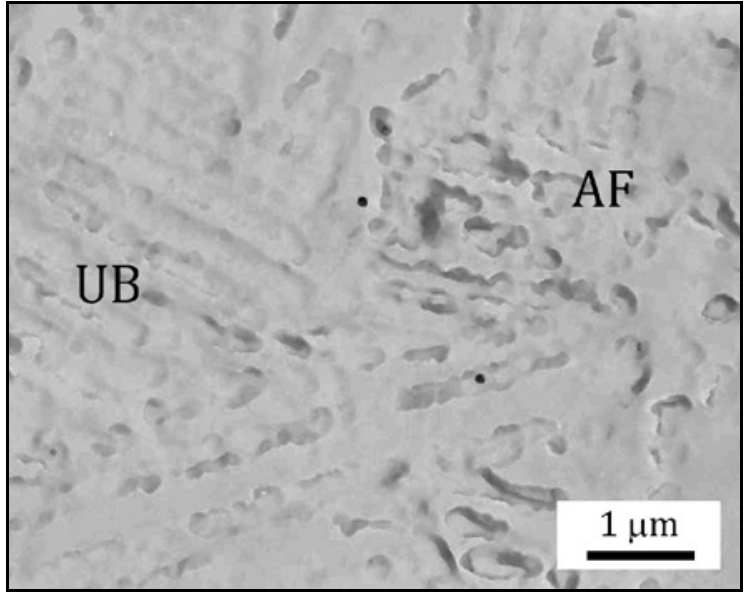

Fig. 14. Upper bainite (UB) and acicular ferrite (AF) in the coarse-grained HAZ near LAD340 steel, TEM.

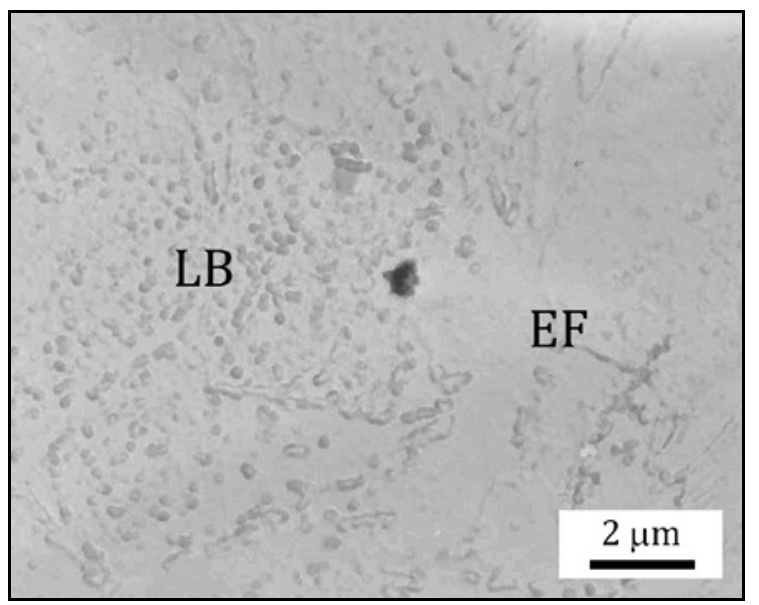

Fig. 15. Lower bainite (LB) and equiaxed ferrite (EF) in the coarse-grained HAZ near LAD340 steel, TEM.

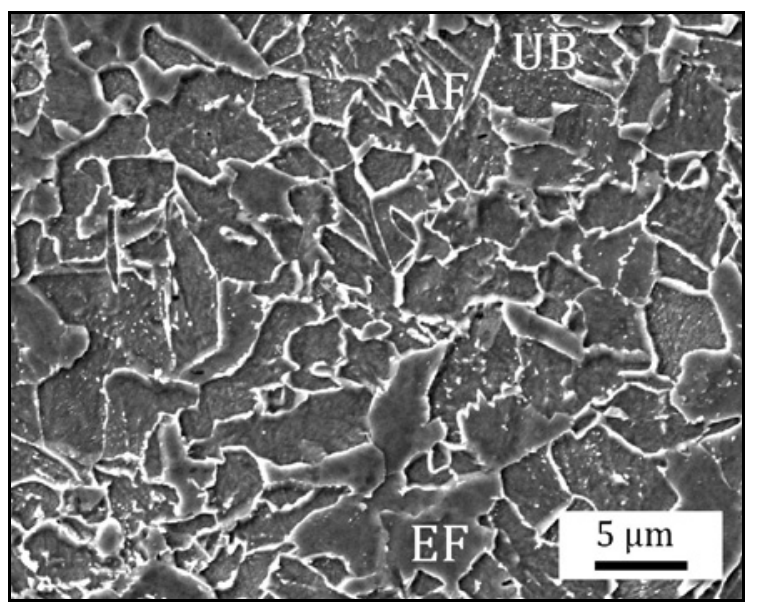

Fig. 16. The microstructure of the fine-grained HAZ near LAD340 steel, SEM (AF - acicular ferrite, EF - equiaxed ferrite, UB - upper bainite). 


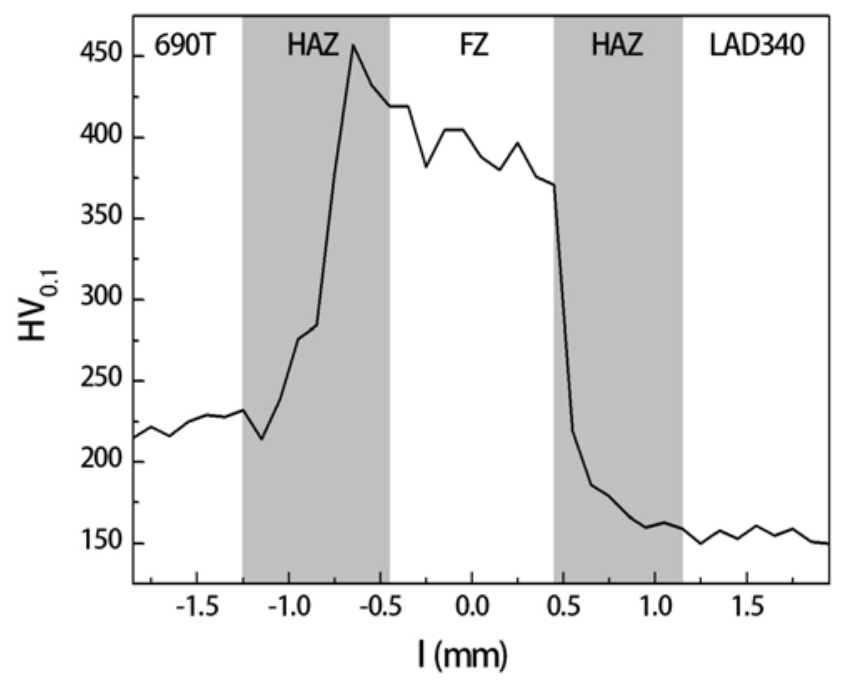

Fig. 17. Microhardness profile across the fibre laser welded joint of $690 \mathrm{~T}$ steel with LAD340 steel.

steel with HSLA LAD340 steel, the microstructure in the fine-grained HAZ near HSLA LAD340 steel consisted mainly of equiaxed ferrite [29]. However, the microstructure in the inter-critical HAZ of HSLA steel with $0.08 \mathrm{C}, 0.8 \mathrm{Mn}, 0.5 \mathrm{Si}$, and $0.05 \mathrm{Al}$ was built of ferrite, carbides, and martensite in work [27].

\subsection{Microhardness profile across the fibre laser welded joint}

The microhardness profile across the transverse cross-section of the fibre laser welded joint is drawn in Fig. 17. The profile has an unsymmetrical shape because of different microhardness of both BMs. The microhardness of $690 \mathrm{~T}$ steel $\mathrm{BM}$ in the interval from 210 to $232 \mathrm{HV}_{0.1}$ represents well the microstructure of TRIP steel with a ferritic matrix and islands of martensite and retained austenite. However, the microhardness in the interval from 150 to $161 \mathrm{HV}_{0.1}$ measured for LAD340 steel represents mainly ferritic microstructure of the HSLA steel. The microhardness values in $\mathrm{FZ}$ are in the interval from 371 to $405 \mathrm{HV}_{0.1}$. The microhardness in HAZ near $690 \mathrm{~T}$ is in the interval from 214 to $457 \mathrm{HV}_{0.1}$, and the microhardness in HAZ near LAD340 steel is from 161 to $371 \mathrm{HV}_{0.1}$. The microhardness of $457 \mathrm{HV}_{0.1}$ is the highest measured value, and it was measured in the coarse-grained region of HAZ near TRIP 690T steel which consists of martensite and lower bainite. The smallest value of $214 \mathrm{HV}_{0.1}$ in the HAZ near $690 \mathrm{~T}$ is in the vicinity of $690 \mathrm{~T}$ steel $\mathrm{BM}$ and represents the softening region of sub-critical HAZ heated below $A_{\mathrm{c} 1}$ critical temperature. The microhardness values confirm the identification of microstructural constituents and can be compared with several works $[26,27,29]$. The microhardness in HAZ near HSLA LAD340 steel was from
181 to $380 \mathrm{HV}_{0.1}$ when fibre laser welding of dualphase DP980 steel with HSLA LAD340 steel at similar welding parameters [29]. The microhardness achieved the value of $304 \mathrm{HV}$ in HAZ near C-Mn micro-alloyed steel [26] and values from 200 to $320 \mathrm{HV}$ in HAZ near HSLA steel with $0.08 \mathrm{C}, 0.8 \mathrm{Mn}, 0.5 \mathrm{Si}$, and $0.05 \mathrm{Al}$ $[27]$.

\subsection{Tensile properties of fibre laser welded joint}

Flat tensile test specimens with FZ in the centre of samples showed the average weld joint strength of $449 \mathrm{MPa}$ and the average elongation at break of $15.5 \%$. The weld strength was higher than the tensile strength of HSLA LAD340 steel (see Tab. 2) which was confirmed by breaking all joints in LAD340 BM. Measured joint elongation was in the interval between the minimal elongation of $690 \mathrm{~T}$ and LAD340 BM (see Tab. 2).

\section{Conclusions}

The fibre laser welding of TRIP 690T steel sheet with a thickness of $1.5 \mathrm{~mm}$ and HSLA LAD340 steel sheet with a thickness of $1.2 \mathrm{~mm}$ was studied with a concentration on microstructure, but microhardness and tensile properties were measured, too. The fibre laser welding using YLS 5000 S-1 solid-state laser enabled to prepare joint consisting of 690T and LAD340 steel with proper macrostructure when using beam power of $3600 \mathrm{~W}$ and welding speed of $70 \mathrm{~mm} \mathrm{~s}^{-1}$. The weld prepared with a fibre laser process was free of macro defects, such as pores and cracks, and its geometry was characterised by a slight undercut at the face on the side of LAD340 steel and root sagging. The microstructure of the joint reflected the concentrations of alloying elements in welded steel sheets. Harder microconstituents were created on the side of TRIP 690T steel with a higher content of alloying elements compared to HSLA LAD340 steel.

The microstructure of the fusion zone consisted of lath microconstituents. Laths of martensite, lower bainite, and occasionally upper bainite were built in packets and blocks within a large columnar grain structure and were the consequence of rapid cooling.

The coarse-grained HAZ near TRIP 690T steel was characterised by coarsening of former austenitic grains. The microstructure was built mainly of martensite and lower bainite. In the fine-grained HAZ near $690 \mathrm{~T}$ steel, the microstructure consisted of martensite, lower bainite, and ferrite. The portion of ferrite increased with the distance from the weld centre and with a decrease of maximal temperature achieved during the welding cycle in the inter-critical temperature interval. 
The microstructure of the coarse-grained HAZ near LAD340 steel was built of acicular ferrite, upper bainite, lower bainite, and equiaxed ferrite which precipitated at former austenitic grain. Predominantly equiaxed ferrite with small areas of acicular ferrite and upper bainite and with small precipitates were observed in the fine-grained region of HAZ near LAD340 steel heated in the inter-critical temperature interval.

Microhardness profile across the transverse crosssection of welded joint was characterised with an unsymmetrical shape, with increased microhardness values in FZ and both HAZs. The maximum microhardness was measured within the HAZ near 690T steel with the value of $457 \mathrm{HV}_{0.1}$ and with the highest concentration of alloying elements. The maximal hardness in the HAZ near LAD340 steel reached $371 \mathrm{HV}_{0.1}$. The hardness in FZ was in the interval from 371 to 405 $\mathrm{HV}_{0.1}$. The tensile strength of the fibre laser welded joints exceeded the strength of the LAD340 steel with all welded specimens failing in the LAD340 BM.

\section{Acknowledgements}

This work was supported by the Slovak Research and Development Agency under contract No. APVV-0281-12. The work was supported by the Ministry of Education, Science, Research and Sport of the Slovak Republic under the VEGA $1 / 0405 / 19$ project. The work was supported by UVP STU Bratislava the ITMS 26240220084 project.

\section{References}

[1] Jia, Q., Guo, W., Wan, Z., Peng, Y., Zou, G., Tian, Z., Zhou, Y. N.: Journal of Materials Processing Technology, 259, 2018, p. 58. doi:10.1016/j.jmatprotec.2018.04.020

[2] Bandyopadhyay, K., Panda, S. K., Saha, D. C., Baltazar-Hernandez, V. H., Zhou, Y. N.: Materials Science \& Engineering A, 652, 2016, p. 250. doi:10.1016/j.msea.2015.11.091

[3] Forouzan, F., Vuorinen, E., Mücklich, F.: Materials Science \& Engineering A, 698, 2017, p. 174. doi:10.1016/j.msea.2017.05.053

[4] Evin, E., Tomáš, M.: Metals, 7, 2017, p. 239. doi:10.3390/met7070239

[5] Gronostajski, Z., Niechajowicz, A., Kuziak, R., Krawczyk, J., Polak, S.: Journal of Materials Processing Technology, 242, 2017, p. 246. doi:10.1016/j.jmatprotec.2016.11.023

[6] Li, W., Ma, L., Peng, P., Jia, Q., Wan, Z., Zhu, Y., Guo, W.: Materials Science \& Engineering A, 717, 2018, p. 124. doi:10.1016/j.msea.2018.01.050

[7] Merklein, M., Johannes, M., Lechner, M., Kuppert, A.: Journal of Materials Processing Technology, 214, 2014, p. 151. doi:10.1016/j.jmatprotec.2013.08.015

[8] Zdravecká, E., Slota, J.: Metals, 9, 2019, p. 91. doi: $10.3390 / \operatorname{met} 9010091$

[9] Xu, F., Sun, G., Li, G., Li, Q.: Journal of Materials Processing Technology, 214, 2014, p. 925. doi:10.1016/j. jmatprotec.2013.11.018
[10] Reisgen, U., Schleser, M., Mokrov, O., Ahmed, E.: Optics \& Laser Technology, 44, 2012, p. 255. doi:10.1016/j.optlastec.2011.06.028

[11] Razmpoosh, M. H., Biro, E., Chen, D. L., Goodwin, F., Zhou, Y.: Materials Characterization, 145, 2018, p. 627. doi:10.1016/j.matchar.2018.09.018

[12] Ariza, E. A., Masoumi, M., Tschiptschin, A. P.: Materials Science \& Engineering A, 713, 2018, p. 223. doi:10.1016/i.msea.2017.12.046

[13] Rossini, M., Russo Spena, P., Cortese, L., Matteis, P., Firrao, D.: Materials Science \& Engineering A, 628, 2015, p. 288. doi:10.1016/j. msea.2015.01.037

[14] Schmitt, J. H., Iung, T.: Comptes Rendus Physique, 19, 2018, p. 641 . doi:10.1016/j.crhy.2018.11.004

[15] Guzman-Aguilera, J. J., Martinez-Gonzalez, C. J., Baltazar-Hernandez, V. H., Basak, S., Panda, S. K., Razmpoosh, M. H., Gerlich, A., Zhou, Y.: Materials Science \& Engineering A, 718, 2018, p. 216. doi:10.1016/j.msea.2018.01.108

[16] Lun, N., Saha, D. C., Macwan, A., Pan, H., Wang, L., Goodwin, F., Zhou, Y.: Materials and Design, 131, 2017, p. 450. doi:10.1016/i.matdes.2017.06.037

[17] Coelho, R. S., Corpas, M., Moreto, J. A., Jahn, A., Standfuß, J., Kaysser-Pyzalla, A., Pinto, H.: Materials Science \& Engineering A, 578, 2013, p. 125. doi:10.1016/j.msea.2013.04.039

[18] Ramesh, M. V. L., Srinivasa Rao, P., Venkateswara Rao, V., Phani Prabhakar, K. V.: Materials Today: Proceedings, 2, 2015, p. 2532. doi:10.1016/j.matpr.2015.07.198

[19] Schroepfer, D., Kannengiesser, T.: Journal of Materials Processing Technology, 227, 2016, p. 49. doi:10.1016/j.jmatprotec.2015.05.003

[20] Hong, K.-M., Shin, Y. C.: Journal of Materials Processing Technology, 245, 2017, p. 46. doi:10.1016/j. jmatprotec.2017.02.008

[21] Guo, W., Li, L., Dong, S., Crowther, D., Thompson, A.: Optics and Laser in Engineering, 91, 2017, p. 1. doi:10.1016/i.optlaseng.2016.11.011

[22] Gong, H., Wang, S., Knysh, P., Korkolis, Y. P.: Materials and Design, 90, 2016, p. 1115. doi:10.1016/j.matdes.2015.11.057

[23] Sinha, A. K., Kim, D. Y., Ceglarek, D.: Optics and Laser in Engineering, 51, 2013, p. 1143. doi:10.1016/j.optlaseng.2013.04.012

[24] Broggiato, G. B., Cortese, L., Nalli, F., Russo Spena, P.: Procedia Engineering, 109, 2015, p. 356. doi:10.1016/j.proeng.2015.06.243

[25] Wang, J., Yang, L., Sun, M., Liu, T., Li, H.: Materials and Design, 90, 2016, p. 642. doi:10.1016/j.matdes.2015.11.006

[26] Wang, X.-N., Chen, C.-J., Wang, H.-S., Zhang, S.-H., Zhang, M., Luo, X.: Journal of Materials Processing Technology, 226, 2015, p. 106. doi:10.1016/i.jmatprotec.2015.07.010

[27] Saha, D. C., Westerbaan, D., Nayak, S. S., Biro, E., Gerlich, A. P., Zhou, Y.: Materials Science and Engineering A, 607, 2014, p. 445. doi:10.1016/j.msea.2014.14.034

[28] Sowards, J. W., Pfeif, E. A., Connolly, M. J., Mc-Colskey, J. D., Miller, S. L., Simonds, B. J., Fekete, J. R.: Materials and Design, 121, 2017, p. 393. doi:10.1016/j.matdes.2017.02.065

[29] Svec, P., Schrek, A.: Strength of Materials, 49, 2017, p. 531. doi:10.1007/s11223-017-9896-y 